\title{
IDENTIFICATION AND ANALYSIS OF RISKS IN TRANSPORT CHAINS
}

\author{
Ana Stažnik* \\ University of Zagreb, Faculty of Transport and Traffic Science, Croatia \\ Darko Babić \\ University of Zagreb, Faculty of Transport and Traffic Science, Croatia \\ Ivona Bajor \\ University of Zagreb, Faculty of Transport and Traffic Science, Croatia
}

By the impact of globalization on the economic sector, and thus on traffic, transport networks are becoming more complex. This leads to a significant connectivity and interdependence of transport chains, which are a series of links and operations that must be performed in specific order to achieve and ensure an optimal flow of goods between the end raw material suppliers and end-users. They can be shown as a complex system which consists of two subsystems, or of the transport process subsystems and transportation process subsystems. These subsystems have their technical, technological and economic characteristics and as such must be synchronized throughout the entire transport chain, regardless of the type of transport chain in question. The complexity of the transport network has changed historically, so there has been a change in the structure of transport chains and an increase in the number of risks that have an adverse effect on the optimal functioning of the transport chains. To minimize the adverse effect of risk on the efficient functioning of the transport chain, companies are taking a number of steps by which the optimization of transport chains can be carried out. So, the companies can be able to choose appropriate methods for risk management in the transport chain, first step is the identification of risks. In this article the identification of risks that are occurring along the transport chain will be shown. Also, the analysis of identified risks will be conducted, according to their impact on the optimal functioning of the transport chain.

Key words: Analysis, Identification, Management, Risk, Transport chains

\section{INTRODUCTION}

Globalization and market dynamics have caused a dislocation of production and involving more and more companies around the world. It also caused a deregulation in traffic and certainly made the access to world markets easier. This resulted in a greater reliance between participants in the supply chain. As the supply chain consists of interconnected and independent companies, the key of connectivity is in the transport chains. It is necessary to continuously control and manage the potential risks that could disrupt the transport chain, and consequently result in a disruption in the supply chain. There are various models of risk assessment and its management, and the choice depends on various factors that may have impact on the functioning of the transport system. Also, there is no unique solution for decision-making related to risks for each transport chain, because it depends on various fac- tors, such as the number of links, phases of the supply chain which it connects, distance etc.

\section{LITERATURE PREVIEW}

From a geographical standpoint, in the past, supply chains, and thus the transport chains were usually regional or national. They were shorter and there was less uncertainty and disruption to flows between starting points and destinations. Because of the increasing dynamics and complexity of the structure of today's transport networks, today's the transport chains are susceptible to many types of risks. This is one reason why many scientists explore the area of identification, impact and methods of reducing risks in all areas, including in the transport system, which is an important link in the supply chain. Research and studies on the identification of risks and the use of methods of risk management in the supply chain can be found in various literature, and in accordance with the theme studied the risk

* University of Zagreb, Faculty of Transport and Traffic Science, Vukelićeva ulica 4, 10000 Zagreb, Croatia; 
management related to the transport system.

Coyle et al in [01] describes the key terms and processes of risk management. In this book, the focus is put on the strategy of risk reduction in transport, as protection of a safer and more efficient supply chain. Besides, in the mentioned book, some of the methods were used in the identification and analysis of risk in transport.

Waters [02] in his book: "Supply Chain Risk Management: Vulnerability and Resiliencein Logistics" says that there are many factors that can cause disruptions in the supply chain. Some events that occurred in previous years and are associated with the risks in the transportation chain are mentioned in this work, like impact of hurricanes on destroying the goods in the Gulf of Mexico, loss of cargo from container ship that was passing through the Indian Ocean etc... These events have received the media attention, and thus pointed out that it is about the events that had a considerable risk consequences and significant impact on the supply chain, such as high costs, late delivery, damage to goods, loss of goods etc.

Maslarić [03] in his dissertation presented systematization of basic theoretical principles in the field of logistics, supply chain management, risk management and risk management in supply chains. This has created a theoretical basis for the definition of the concept of logistics risks in supply chains and the development of models for their management.

Khan and Burnes [04] develop a research agenda for risk and supply chain management. These authors show that there are a number of key debates in the general literature on risk, especially in terms of qualitative versus quantitative approaches, which need to be recognized by those seeking to apply risk theory and risk management approaches to supply chains. In addition, they show that the application of risk theory to supply chain management is still in its early stages andthat the models of supply chain risk which have been proposed need to be tested empirically.

Jüttner [05] in her article: "Supply chain risk management: Understanding the business requirements from a practitioner perspective" described the findings from an exploratory quantitative survey and qualitative focus group discussions with supply chain managers. Some issues of supply chain risk managemnt are derived and structured along the three conceptual levels of "philosophy", "principles" and "processes". This survey showed that 44 per cent of all eight responding companies expect the vulnerability of their supply chains to increase in the next five years. However, the concept of supply chain risk management is still in its infancy.

Vilko and Hallikas [06] in their paper presented preliminary research concepts and findings concerning the identification and analysis of risks in multimodal supply chains. Their research approach is holistic, and incorporates perspectives from different parts of the chain. The multimodal maritime supply chain in focus runs from the Gulf of Finland to the Finnish mainland. They maped the process and the structure, and presented a new framework for categorizing the risks in terms of their driver factors in order to assess the overall impact on the performance of the supply chain. Also, theiy analyzed the risk impacts in terms of delays in the chain by means of MonteCarlo-based simulation.

Zhao et al in their study [07] applied Bayesian networks to prioritize the factors that influence hazardous material (Hazmat) transportation accidents. The Bayesian network structure was built based on expert knowledge using Dempster-Shafer evidence theory, and the structure was modified based on a test for conditional independence. They collected and analyzed 94 cases of Chinese Hazmat transportation accidents to compute the posterior probability of each factor using the expectation-maximization learning algorithm. They found that the three most influential factors in Hazmat transportation accidents were human factors, the transport vehicle and facilities, and packing and loading of the Hazmat. These findings provide an empirically supported theoretical basis for Hazmat transportation corporations to take corrective and preventative measures to reduce the risk of accidents.

Sun et al in [08] present a quality risk management model for a supplier-assembler structure supply chain. To mitigate quality risks, supply chain members are coordinated by sharing their information. To be able to respond quickly to the assembler's feedback (e.g., quality problems) has become a key point of a supplier's competitive edge. This ability is also useful for removing bottlenecks among the supply chain. In the setting of a due-date to treat an assignable cause, because idle risk and delay risk have a trade-off 
relationship, find out the optimal due-date becomes a problem of great interest to the supplier. They develop a P-chart solution model to help suppliers find out the optimal due-date that minimizes the total cost. They also clarify the relations among various risks by analyzing proposed model. Sun et all find that a longer due-time should be set when either the sampling interval is longer or a high quality is demanded.

Ennouri [9] developed his paper to clarify the basics of risk management through a short new suggestion of literature review for risk management. His justification of this attempt is that this area is the most discussed in our days and it is impossible to present all definition of the risk concept, he has tried to collect the most recent studies in his paper.

\section{THEORETICAL BASIS OF RISK}

The problem of risk management is a global problem that requires global solutions. In addition to these authors who were engaged in research on the topic, there is an international legal regulation which prescribe requirements of risk management. Definitions of general terms related to risk management are provided in the international norm ISO Guide 73:2009 - Risk Management Guidelines. The principles and general guidelines of risk management are defined in international norm ISO 31000:2009 - Risk Management. This norm relates to any type of risk, regardless of the nature, the positive or negative effects, and is not specific to a particular activity. Risk assessment methods, assessment process and risk assessment techniques are defined in the International Standard ISO 31010:2009 - Risk Managemenet - Risks Assesment Techniques. The risk management in supply chains is defined in international norm ISO 28000:2007 - Specification for security management systems of the supply chain. According to [02], risk is the probability that an unexpected event harms business organization and is defined as a function of the level of uncertainty, obtained by means of probabilities or frequency and size of the impact of a given event. According to [10], risk is defined through three questions:

What can happen, and what can go wrong? What is the probability that this will happen? If it happens, what are the consequences?

So, risk is a combination of the probability of events and negative consequences, where is tried to reduce the effect of one to another as much as possible [11], and it is shown in (1).

$R=f\left(S_{i}, L_{i}, X_{i}\right)$

Where:

$S_{i}$ - identification and description of potential events; $L_{i}$ - probability of events; $X_{i}$ - consequence or impact assessments of events.

Consequently, Misita [12] in her article defined risk as product of probability and consequence of certain events, which can be expressed in formula (2):

$\mathrm{R}=\mathrm{P} * \mathrm{Q}$

Where:

$\mathrm{R}$ - risk; $\mathrm{P}$ - probability a particular event; $\mathrm{Q}$ - consequences of particular event.

Also, the risk can be shown as the product of probability of an unwanted event and the consequences of the realization of the event, (3):

$\mathrm{R}=\mathrm{P}$ * I

Where:

$\mathrm{R}$ - risk; $\mathrm{P}$ - probability of realization of unwanted events; I - impact of realization of events.

According to (3), it can be said that the risk exists only if there is a probability of an unplanned and unwanted event and the consequences of this event. If one of the above mentioned parameters does not exist, there is no presence of risk. If there is a probability and a consequence it is possible to determine the risk as failure to fulfill the objective. The Figure 1 shows the definition of risk and its impact on the fulfillment of the objective.

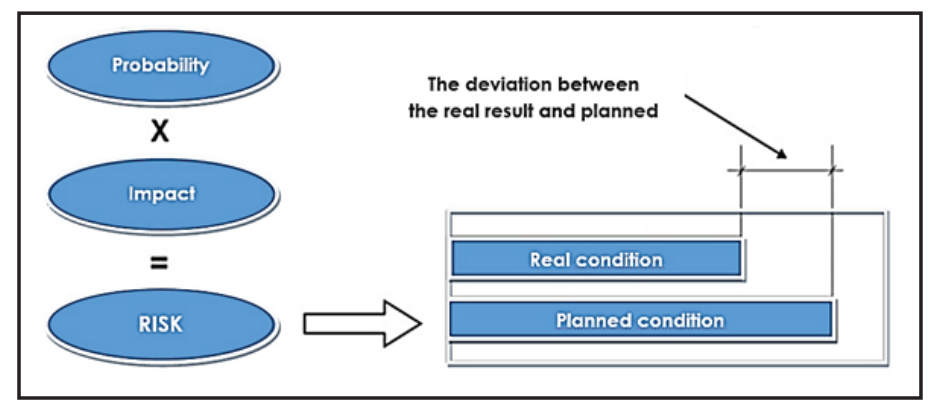

Figure 1: The definition of risk and its impact on the fulfillment of the objective 


\section{METHODS OF RISK ASSESSMENT IN THE TRANSPORT CHAIN}

Risk assessment is a critical process to identify and evaluate events, e.g. critical technical risks that could influence predefined objectives. This process includes two relevant activities: risk identification and risk analysis [13].

Identification of risks represents the initial risk assessment process. Identification is the process of determining the classification of risk events in the future that could have a negative impact to transport chain and thus result in disruption in the supply chain. In general, there are two possible approaches how to identify and create a list of risk, considering included scope [11]:

- „Top-down“- an approach that is based on the identification of all importatant risks by the management which manages risks throughout the transport chain.

- „Bottom-up“- An approach where risks are defined by managers who manage each link in the chain.

These two approaches are complementary. At the top-down approach identifies the main risks that are related to the whole transport chain, and at the bottom-up identifies risks that are associated with the activities in each link in the transport chain. Some of the techniques that can be used in the process of identification of risks in the transport chain are surveying, brainstorming, viewing the historical problems, the Delphi Method, What-If Analysis, PGA method, Event tree analysis, simulation etc.

After identifying risks and making the list of risks, second step is their analysis in terms of potential impact or consequence. The aim is to define prioritization of risks, in terms of giving priority in treating risks with the highest probability of occurrence and the highest level of of influence.

In the analysis of risk, there are qualitative and quantitative methods. Qualitative methods of risk analysis can make the primary risk assessment fast and economical way. By using such methods, it is possible to classify every risk in terms of low, medium or high probability and impact.

Besides, qualitative risk analysis techniques are used in situations where there is no information about previous risk events. These techniques are based on subjective and empirical assessment related to the risk probability of events and their consequences.
The most commonly used qualitative risk analysis method is a Risk Matrix, where abscissa of the matrix shows the level of consequences of the analyzed risk event, and the ordinate shows the probability of realization of risk event [3]. Besides the risk matrix, a risk matrix with predefined values is used which is shown through three parameters (asset values, threat, vulnerability levels).

According to [03], each of these parameters is observed in relation to the possible consequences, and the threat is observed in relation to the corresponding vulnerability, and it is shown in (4):

$R=f\left(A V_{l}, V_{l, P}, V_{l, V, P}\right)$

All parameters are quantified optionally according to its own estimates. For determination of value of resources, the numerical values in the range of 0 (low) to 4 (very large) were used, and to quantity the vulnerabilities and threats ranges from 0 (low level) to 2 (high) were used. The risk level is defined by the sum of the parameter values according to (5):

$\mathrm{R}=\mathrm{AV}+\mathrm{V}+\mathrm{T}$

Qualitative risk analysis is often a basis for quantitative analysis. Quantitative risk analysis is carried out only for those risks that are selected by qualitative analysis as risks with the greatest impact on transport chain.

According to [01], the selected risks are analysed in detail using quantitative risk analysis methods and for every risk is assigned a numerical estimate frequency, probability and consequences. Quantitative methods are usually based on mathematical calculations, where the uncertainties are shown like random variables, and as such have unpredictable values. Random variables can only be determined in probabilities in which they assume a value. Monte Carlo method and Event tree analysis (ETA) are methods that are often applied in quantitative risk analysis.

\section{IDENTIFICATION RISK IN TRANSPORT CHAINS}

For the reasearch purpose, data related to the incidents that have occurred in the transport chain to and from Germany, was collected, in the period from early 2010 to the end of 2013. The transported goods were insured by an insurance company. Name and other basic information about the insurance company are not listed in order to protect trade secrets of insurance company and confidential data collected for the 
purpose of writing this paper. Through those four years there were 1,129 incidents that resulted in the additional costs due to damage and loss of freight, and other causes that affect the delay, and with that reduce the continuity along the transport chain. These incidents took place in the road, rail, maritime and air transport of freigth, followed by transshipment in logistics distribution centers (LDC) or warehouses that are intended for transshipment, air and maritime ports and railway stations. Incidents related to damage or loss of freight, and the technical problems of transport equipment, the impact of natural disasters and political impact which caused the failure in the transport process, then the number of traffic accidents, the impact of temperature changes for the longer supply chains, errors caused by the human factor in the organization of the transportation process, etc.. Situations listed above represent a kind of incidents where the freight was damaged, meaning the number of incidents that had resulted in damage to the freight due to inadequate security and securing cargo in the transport vehicle during transport or due to harsh and improper cargo handling and transshipment means during transshipment. This means the number of incidents of minor damage to the product and packaging as well as events with complete destruction of the product. The loss of freight refers to incidents involving pilferage and significant theft, such as stealing a certain amount of transport freight, and grand theft whereby entire transport freight gets stolen. The above group includes incidents involving loss of freight due to the ejection of containers from the ship due to the potential risk of hazardous situations and loss of freight on transshipment locations due to improper organization. Technical problems are a group of incidents where there has been a failure of the means of transport, involving vehicles and transport-manipulation means intended for transshipment of freight, which caused additional costs and delays that have further consequences in the transport, and the supply chain. Natural disasters include a number of incidents involving incidents such as floods, fires, storms etc. Traffic accidents include a number of incidents relating to collisions, overturning transport means, sinking, skidding from road and rail etc. The group of political influences included the number of incident situations that are associated with the prohibition of transport in some, then the terrorist attacks, while the rest is considered to be number of incidents that have occurred because of a human factor in the organization of the transport process, errors in information systems, false documentation etc. All these incident situations have had an impact on the functionality of the transport chain, and thus the connection between all links in the supply chain. Table 1 shows the number of incident situations by type of event, in transport and transshipment process in the transport chain, according to the data obtained.

Table 1: Total number of incidents in the transport and transshipment process according to the type of incidents

\begin{tabular}{|c|c|c|c|c|c|c|c|c|c|}
\hline \multirow{2}{*}{ Types of incident } & \multicolumn{4}{|c|}{ Transport } & \multicolumn{4}{|c|}{ Transshipment } & \multirow{2}{*}{ Total } \\
\hline & Road & Maritime & Rail & Air & LDC & Seaport & Rail terminal & Airport & \\
\hline Damage to cargo & 65 & 51 & 22 & 8 & 218 & 164 & 117 & 58 & 703 \\
\hline Loss of cargo & 43 & 19 & 6 & 2 & 61 & 33 & 24 & 11 & 199 \\
\hline Technical problems & 12 & 3 & 1 & 1 & 9 & 11 & 6 & 4 & 47 \\
\hline Natural hazards & 8 & 6 & 3 & 1 & 2 & 1 & 1 & 0 & 22 \\
\hline Transport accidents & 43 & 8 & 3 & 0 & 4 & 5 & 3 & 0 & 66 \\
\hline Political influence & 12 & 0 & 3 & 0 & 2 & 0 & 0 & 1 & 18 \\
\hline Other & 21 & 13 & 6 & 7 & 18 & 3 & 4 & 2 & 74 \\
\hline Total & \multicolumn{4}{|c|}{367} & \multicolumn{4}{|c|}{762} & 1129 \\
\hline
\end{tabular}

According to the data from Table 1, a graph can be defined, that represents percentage of incident situations by type of transport process. Figure 2 shows that during the transshipment a total of 762 accidental events have occured, or $67.5 \%$, while during the transportation a total of 367 , or $32.5 \%$.

Furthermore, it can be noticed how damage to the freight with a total of $62.3 \%$, has the highest percentage in the total number of incident events in all parts of the transport chain. According to Figure 3 , the percentage of incidental situations in the transportation chain by type of these events is shown in detail, were can be seen how, after damage to freight, the largest percentage of incidental situations is related to the loss of freight $(17.6 \%)$, followed by other incidents ( $6.6 \%)$, traffic accidents (5.8\%), the technical 
problems of transport equipment (4.2\%), and natural disasters, with $1.9 \%$, and political influence, with $1.6 \%$, with the lowest percentage in the total number of incident situations.

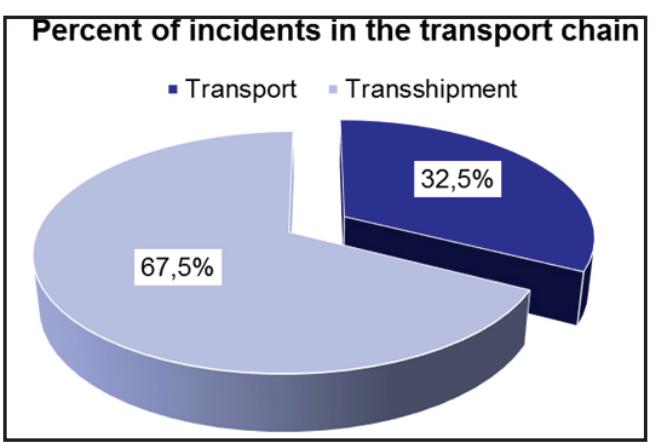

Figure 2: Percent of accidental events according to type of transport process

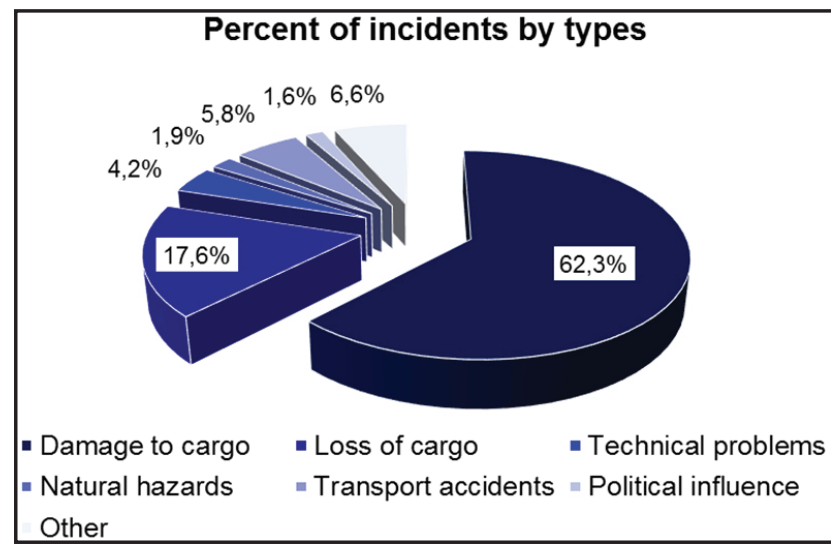

Figure 3: Percent of incidents according to type of incidents

Damage to freight usually happens in the LDC's and seaports, where the percentage of total incidents is $19.31 \%$ and $14.53 \%$. Damage to the freight in road transport also has a significant percentage, in overall incidents in all parts of the transport chain. Generally, as the road and maritime transport is most used in the transport of freight, according to these data, it can be concluded that in those parts of the transport chain most incidents occur. According to Table 2 , which shows the percentage of a particular type of incidents for each part of the transport chain, which is included in the data, a graphical representation that I made shows the percentage of incidents to certain parts of the transport chain (Figure 4). In this graph, we can see that the most incidents were events in LDC's, a total of $27.81 \%$, then the seaports $(19.22 \%)$, road transport $(18.07 \%)$, railway stations $(13,73 \%)$, maritime transport $(8.88 \%)$, while in the remaining parts of the transport chain a total of $12.31 \%$ of incidental events is recorded.

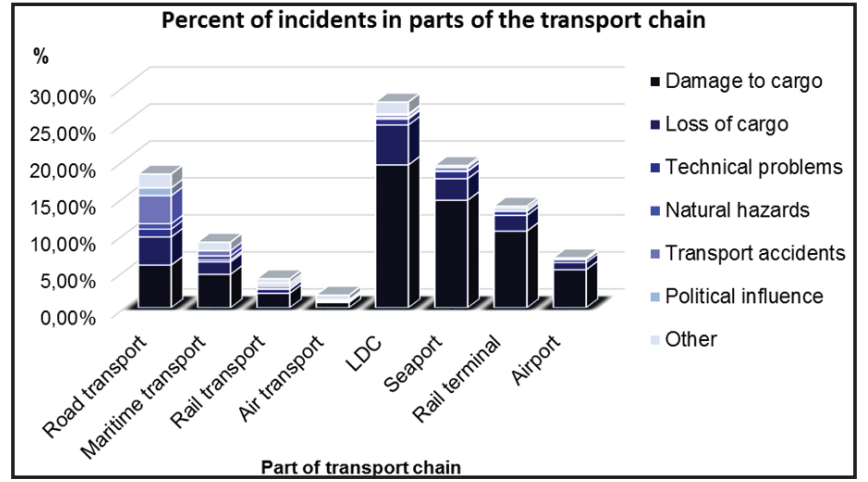

Figure 4: Percent of incidents according to part of transport chain

It can be concluded that the critical point in the transport chain, given the frequency of incidents, is the LDC. The next critical point is a seaport, which could be expected, since the maritime and road transport are the most common means of transporting freight, so the incidents are actually happening on the intersections of listed parts of the transport chain.

\section{LIST OF IDENTIFIED RISKS}

By the processed data can be concluded that there are many risks in the transport chains that could cause damage and have a negative affect on its functioning. According to the processed data related to the incidents in transport chains, risks can be classified into seven categories and presented in a list:

- Risk of damage to cargo,

- Risk of loss of cargo,

- Risk of technical problems of transport equipment,

- Risk of natural hazards,

- Risk of transportation accidents,

- Risk of political influence,

- Risk of other adverse occurrences.

\section{ANALYSIS OF IDENTIFIED RISKS USING A MATRIX OF PREDEFINED VALUES}

According to the processed data related to the number of incidents along the transport chain incidents that represent a risk in the future were determined. Matrix predefined value belongs to the group of qualitative methods, which means that the level of risk in the transport chain is to be estimated based on the relative size of the parameters. 
Table 2: Percent of incidents in parts of the transport chain according to type of incident

\begin{tabular}{|c|c|c|c|c|c|c|c|c|c|}
\hline \multirow{2}{*}{ Types of incident } & \multicolumn{4}{|c|}{ Transport } & \multicolumn{4}{|c|}{ Transshipment } & \multirow{2}{*}{ Total } \\
\hline & Road & Maritime & Rail & Air & LDC & Seaport & Rail terminal & Airport & \\
\hline Damage to cargo & $5,76 \%$ & $4,52 \%$ & $1,95 \%$ & $0,71 \%$ & $19,31 \%$ & $14,53 \%$ & $10,36 \%$ & $5,14 \%$ & $62,27 \%$ \\
\hline Loss of cargo & $3,81 \%$ & $1,68 \%$ & $0,53 \%$ & $0,18 \%$ & $5,40 \%$ & $2,92 \%$ & $2,13 \%$ & $0,97 \%$ & $17,63 \%$ \\
\hline Technical problems & $1,06 \%$ & $0,27 \%$ & $0,09 \%$ & $0,09 \%$ & $0,80 \%$ & $0,97 \%$ & $0,53 \%$ & $0,35 \%$ & $4,16 \%$ \\
\hline Natural hazards & $0,71 \%$ & $0,53 \%$ & $0,27 \%$ & $0,09 \%$ & $0,18 \%$ & $0,09 \%$ & $0,09 \%$ & $0,00 \%$ & $1,95 \%$ \\
\hline Transport accidents & $3,81 \%$ & $0,71 \%$ & $0,27 \%$ & $0,00 \%$ & $0,35 \%$ & $0,44 \%$ & $0,27 \%$ & $0,00 \%$ & $5,85 \%$ \\
\hline Political influence & $1,06 \%$ & $0,00 \%$ & $0,27 \%$ & $0,00 \%$ & $0,18 \%$ & $0,00 \%$ & $0,00 \%$ & $0,09 \%$ & $1,59 \%$ \\
\hline Other & $1,86 \%$ & $1,15 \%$ & $0,53 \%$ & $0,62 \%$ & $1,59 \%$ & $0,27 \%$ & $0,35 \%$ & $0,18 \%$ & $6,55 \%$ \\
\hline Total & $18,07 \%$ & $8,86 \%$ & $3,90 \%$ & $1,68 \%$ & $27,81 \%$ & $19,22 \%$ & $13,73 \%$ & $6,73 \%$ & $100,00 \%$ \\
\hline
\end{tabular}

As mantioned above, this method can be displayed through three parameters, where:

- $\mathrm{AV}$ - value of risk or impact on the transport chain,

- $\mathrm{T}$ - threat in the transport chain,

- V - vulnerability, which means the analysis of the link in the transport chain in which the risks were identified.

The value of risk can be defined as the level of an unwanted event, and taking into account the extent of damage at a defined type of incidents a value of risk for each group of incidents was determined. The value of risk is divided into seven categories, where 1 represents that particular incident had a small adverse effect on the transport chain, while 6 is the value of a particular incident event that had large adverse effects on the transport chain. Table 3 shows the values defined risk by type of incident.

Table 3: The predefined value of risk

\begin{tabular}{|c|c|}
\hline Types of risk & Value of risk \\
\hline \hline Political influence & 0 \\
\hline Other & 1 \\
\hline Natural hazards & 2 \\
\hline Loss of cargo & 3 \\
\hline Technical problems & 4 \\
\hline Transport accidents & 5 \\
\hline Damage to cargo & 6 \\
\hline
\end{tabular}

Threats are related to the frequency of risks, so they are classified into three categories. Low level of threat represents a rare occurrence of risk, while a high level of threat presents a frequent occurrence of risk. The levels of a threat are defined according to the frequency of incidents and events and are shown in Table 4.

Table 4: The predefined level of threat

\begin{tabular}{|c|c|}
\hline Types of threat & Level of threat \\
\hline Low & 0 \\
\hline Medium & 1 \\
\hline High & 2 \\
\hline
\end{tabular}

Journal of Applied Engineering Science 15(2017)1, 414
The vulnerability represents a link in the transport chain in which the risks are identified, and are grouped into four categories, where 0 represents a link in the transport chain where the probability of risks is minimal, and 3 represents a link in the transport chain where there is a high probability of risk. The probability of risk is defined according to historical records, according to the presented frequency of incidents. Table 5 shows the predefined level of vulnerability of the transport chain.

Table 5: The predefined level of vulnerability

\begin{tabular}{|c|c|}
\hline $\begin{array}{c}\text { Part of transport } \\
\text { chain }\end{array}$ & Level of vulnerability \\
\hline $\begin{array}{c}\text { Rail transport } \\
\text { Air transport }\end{array}$ & 0 \\
\hline $\begin{array}{c}\text { Maritime transport } \\
\text { Airport }\end{array}$ & 1 \\
\hline $\begin{array}{c}\text { Road transport } \\
\text { Rail terminal }\end{array}$ & 2 \\
\hline LDC \\
Seaport
\end{tabular}

These parameters are crucial in the calculation of risk levels, and thus an analysis is carried out that provides an answer to the question, which is the highest and the lowest risk level. Using a formula (5) the risk levels in the transportation chain can be calculated and results are shown by the matrix, which can be seen in Table 6 .

This model shows the three groups of risk, depending on the considered combined threat vulnerability. The most critical risks are marked by colour red (risk levels 8-11), medium critical risks are marked in yellow (risk levels 4-7), and the least critical risks green (risk levels 0-3). According to the formula (5), the minimum and maximum risk levels in the transportation chain are:

$R_{\text {MIN }}=A V_{\text {MIN }}+V_{\text {MIN }}+T_{\text {MIN }}=0+0+0=0$

$R_{\text {MAX }}=A V_{\text {MAX }}+V_{M A X}+T_{M A X}=6+2+3=11$ 
Table 6: Risk matrix with predefined values in the transport chains

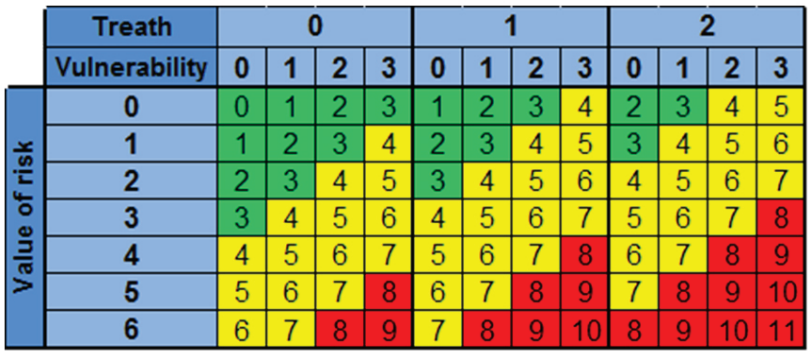

The value 0 indicates that due to the low probability of the risk of political interference in the air and rail transportation the risk level is minimal, and therefore does not represent a significant ef- fect on the transport chain. The value of 11 shows that the LDC and seaports have a high probability of risk of the freight damage so there can appear adverse effects on the transport chain.

List of risk levels according to calculations based on the formula (5) and by the shown ranges of treats is shown in Table 7 and is displaced in the transport chain impact.

From Table 7 it can be seen that the biggest problems in the transport chains are the risk levels of damage to the freight, traffic accidents and technical problems of transport equipment. Also, the risk of damage to the freight is high in each segment of the transport chain.

Table 7: List of risks according to impact to the transport chain

\begin{tabular}{|c|c|c|}
\hline $\begin{array}{c}\text { Part of transport } \\
\text { chain }\end{array}$ & Types of risk & $\begin{array}{l}\text { Level } \\
\text { of risk }\end{array}$ \\
\hline LDC & Damage to cargo & 11 \\
\hline Seaport & Damage to cargo & 11 \\
\hline Road transport & Damage to cargo & 10 \\
\hline Seaport & Technical problems & 9 \\
\hline Maritime transport & Damage to cargo & 9 \\
\hline Rail terminal & Damage to cargo & 8 \\
\hline Road transport & $\begin{array}{l}\text { Transport } \\
\text { accidents }\end{array}$ & 8 \\
\hline LDC & $\begin{array}{l}\text { Technical } \\
\text { problems }\end{array}$ & 8 \\
\hline Rail terminal & $\begin{array}{l}\text { Transport } \\
\text { accidents }\end{array}$ & 8 \\
\hline LDC & $\begin{array}{l}\text { Transport } \\
\text { accidents }\end{array}$ & 8 \\
\hline LDC & Loss of cargo & 8 \\
\hline Airport & Damage to cargo & 7 \\
\hline Road transport & $\begin{array}{l}\text { Technical } \\
\text { problems }\end{array}$ & 7 \\
\hline Seaport & Loss of cargo & 7 \\
\hline Maritime transport & $\begin{array}{l}\text { Transport } \\
\text { accidents }\end{array}$ & 7 \\
\hline Airport & $\begin{array}{l}\text { Transport } \\
\text { accidents }\end{array}$ & 7 \\
\hline Road transport & Loss of cargo & 7 \\
\hline LDC & Natural hazards & 7 \\
\hline Seaport & $\begin{array}{l}\text { Transport } \\
\text { accidents }\end{array}$ & 6 \\
\hline Air transport & Damage to cargo & 6 \\
\hline Rail terminal & $\begin{array}{l}\text { Technical } \\
\text { problems }\end{array}$ & 6 \\
\hline Rail transport & Damage to cargo & 6 \\
\hline Rail terminal & Loss of cargo & 6 \\
\hline LDC & Other & 6 \\
\hline
\end{tabular}

\begin{tabular}{|c|c|c|}
\hline $\begin{array}{c}\text { Part of transport } \\
\text { chain }\end{array}$ & Types of risk & $\begin{array}{l}\text { Level } \\
\text { of risk }\end{array}$ \\
\hline Seaport & Natural hazards & 5 \\
\hline Maritime transport & Technical problems & 5 \\
\hline Airport & Technical problems & 5 \\
\hline Air transport & Transport accidents & 5 \\
\hline Rail transport & Transport accidents & 5 \\
\hline Seaport & Other & 5 \\
\hline Rail terminal & Natural hazards & 5 \\
\hline Rail transport & Technical problems & 5 \\
\hline Maritime transport & Loss of cargo & 4 \\
\hline Air transport & Transport accidents & 4 \\
\hline Road transport & Other & 4 \\
\hline LDC & Political influence & 4 \\
\hline Seaport & Political influence & 4 \\
\hline Maritime transport & Natural hazards & 4 \\
\hline Airport & Natural hazards & 4 \\
\hline Rail transport & Loss of cargo & 4 \\
\hline Road transport & Political influence & 4 \\
\hline Rail terminal & Other & 3 \\
\hline Road transport & Natural hazards & 3 \\
\hline Airport & Loss of cargo & 3 \\
\hline Maritime transport & Other & 2 \\
\hline Airport & Other & 2 \\
\hline Air transport & Natural hazards & 2 \\
\hline Rail terminal & Political influence & 2 \\
\hline Rail transport & Natural hazards & 2 \\
\hline Maritime transport & Political influence & 1 \\
\hline Airport & Political influence & 1 \\
\hline Air transport & Loss of cargo & 1 \\
\hline Air transport & Other & 1 \\
\hline Rail transport & Other & 1 \\
\hline Air transport & Political influence & 0 \\
\hline Rail transport & Political influence & 0 \\
\hline
\end{tabular}




\section{CONCLUSION}

From a geographical standpoint, in the past, supply chains, and with that transport chains, were usually regional or national, so they were shorter and there were less uncertainty and disruption to flows between origin and destination. Today suply chains are sensitive to many types of risks because of increasing dynamics and complexity of the structure of today's transport networks. That is one of the reasons why many scientists are researchig the area of identification, impact and ways to reduce risk level in all areas, including transport systems which is an important link in the supply chains.

Transport chains can provide a great efficiency of supply chains, and can, if risks are well managed, lead to large reduction of costs, which can be reflected in an increase in profits to all participants of the supply chain. If accidents often occur during the transport, significant losses can apear for all profitable organizations as well as for customers. Loss for the customer can be expressed in the unavailability of the product on the shelves, but also with increase of prices of the product itself. By analyzing incidents that have caused adverse events in the transport process, it is possible to identify critical points in the transport chain and to define risks that affect it.

In this paper, 7 key risks that appear along the transport chain were identified, and they are the risks of accidents, technical problems of transport, political influences, natural disasters, loss and damage to cargo and other adverse events. It is shown that out of all the defined risks the risks of damage to the cargo, traffic accidents, and technical problems of transport equipmen, are the biggest problems in the transport chain. It can be seen that the risk of damage to the freight, is at high level in every segment in the transport chain.

According to the data, it can be concluded that the critical point in the transport chain, when frequency of incidents is high, is actually LDC. The next critical point is the maritime port, which itself is predictable, because from the processed data in this paper, maritime and road transport are the most common forms of tranpsort, so incidents are actually happening on the intersections of those parts of the transport chain.

This paper coverd data on the usual routes on which the subject is insured by insurence company. Therefore, it is important to note that a de- fined risk levels, that are obtained by predefined matrix values and they are valid only for the territory covered by the insurance company. Model for risk analysis, presented by predefined matrix value, can also be used in other transport chains, but it is necessary to redefine the parameters according to the data related to other transport chains.

As mentioned before, qualitative risk analysis is often a foundation for quantitative analysis. This qualitative analysis, if conducted in transport chains can reperesent the basis for further risk analysis by quantitative methods. That kind of analysis would give a more detailed and accurate overview of risks along the transport chain on which the research was carried out.

\section{REFERENCES}

1) J.J. Coyle, R.A. Novack, B.J Gibson, E.J. Bardi: "Transportation: A supply Chain Perspective", 7th ed., South Western Cengage Publishing, Mason, Ohio, 2011, pp. 301

2) Waters, D: Supply chain risk management: vulnerability and resilience in logistics. Kogan Page, United Kingdom and USA, 2007

3) Maslarić, M.: Razvoj modela upravljanja logističkim rizicima u lancima snabdijevanja, Doktorska disertacija, Univerzitet u Novom Sadu, Fakultet tehničkih nauka, Novi Sad, 2014., pp. 73.

4) Khan, O., Burnes, B.: Risk and supply chain management: creating a research agenda, International Journal of Logistics Management, Vol. 18, No. 2, pp. 197 - 216., 2007

5) Jüttner, U.: "Supply chain risk management: Understanding the business requirements from a practitioner perspective", The International Journal of Logistics Management, Vol. 16 Iss: ,1 pp.120 - 141, 2005

6) Vilko, J.P.P., Hallikas J.M.: Risk assessment in multimodal supply chains, Original Research Article, International Journal of Production Economics, Volume 140, Issue 2, December 2012, Pages 586-595

7) Zhao L., Wang X., Qian Y.: Analysis of factors that influence hazardous material transportation accidents based on Bayesian networks: A case study in China, Safety Science (50), 1049-1055, 2012

8) Sun J., Matsui M., Yin Y.: Supplier risk management: An economic model of P-chart 
considered due-date and quality risks, International Journal of Production Economics (139), 58-64, 2012

9) Ennouri W.: Risks management: New literature review, Polish Journal of Management Studies, vol. 8/2013, 2013

10) Paulsson, U.: On managing disruption risks in the supply chain-the DRISC model, PhD thesis, Department of Industrial Management and Logistics, Engineering Logistics, Lund University, Sweden, 2007

11) Risk identification and assessment process: http://www.wikinvest.com/stock/Allied_Irish_
Banks_\%28AIB\%29/Risk_Identification_Assessment_Process (20.04.2016.)

12) Misita M., Sebzssia G., Milovanović M.: A combining genetic learning algorithm and risk matrix model using in optimal production program, Journal of Applied Engineering Science 10 (3), 147-152

13) Sousa, S., Nunes, E., Lopes, I.: Measuring and managing operational risk in industrial processes, FME Transactions, Volume 43, Issue 4, 2015, Pages 295-302

Paper sent to revision: 24.10.2016.

Paper ready for publication: 12.01.2017. 